\title{
EFEKTIVITAS MOBILE LEARNING DENGAN GOOGLE CLASSROOM DISERTAI TUTOR SEBAYA PADA MATA KULIAH FISIKA DASAR
}

\author{
Dewi Juita1, Yusmaridi $M^{2}$ \\ ${ }^{1}$ Tadris Biologi, FTIK, IAIN Kerinci, Jl. Kapten Muradi Desa Sumur Gedang, Sungai Penuh \\ ${ }^{2}$ Tadris Fisika, FTIK, UIN Imam Bonjol Padang, Jl. Prof. Mahmud Yunus Lubuk Lintah \\ E-mail: dewijuita@iainkerinci.ac.id
}

\begin{abstract}
ABSTRAK
Era revolusi industri 4.0 menghendaki pembelajaran berbasis teknologi. Pembelajaran fisika dasar di Jurusan Tadris Biologi IAIN Kerinci belum menggunakan teknologi dalam pembelajaran. Ilmu fisika juga dianggap sulit oleh mahasiswa. Solusi yang digunakan adalah pembelajaran mobile menggunakan platform google classroom disertai tutor sebaya. Penelitian ini bertujuan untuk mengetahui tanggapan mahasiswa terhadap penggunaan mobile learning dengan google classroom disertai tutor sebaya serta efektivitas penggunaan mobile learning dengan google classroom disertai tutor sebaya dalam meningkatkan hasil belajar fisika mahasiswa. Metode penelitian yang digunakan adalah metode pre experimental dengan menggunakan instrumen angket tanggapan mahasiswa dan soal hasil belajar berbentuk essay. Hasil penelitian menunjukkan bahwa hampir semua mahasiswa menyetujui penggunaan mobile learning dengan google classroom disertai tutor sebaya praktis, efisien, memberikan pemahaman konsep fisika lebih baik, dapat memotivasi, lebih mendisiplinkan, dan dapat membiana hubungan yang lebih baik dengan rekan sejawat. Selanjutnya, penggunaan mobile learning dengan google classroom disertai tutor sebaya ini efektif dalam meningkatkan hasil belajar fisika mahasiswa dalam kategori sedang dengan nilai $<\mathrm{N}-$ Gain $>0,53$.
\end{abstract}

Kata kunci: mobile learning, google classroom, tutor sebaya, fisika dasar

\begin{abstract}
The era of the industrial revolution 4.0 requires technology-based learning. Basic physics learning in the Tadris Biology department of IAIN Kerinci has not used technology in learning. Physics is also considered difficult by students. The solution used is mobile learning using the Google classroom platform accompanied by peer tutors. This study aims to determine student responses to the use of mobile learning with google classroom accompanied by peer speech and the effectiveness of using mobile learning with google classroom accompanied by peer speech in improving student physics learning outcomes. The research method used was a pre-experimental method by using a student questionnaire response instrument and learning outcomes questions in the form of essays. The results showed that almost all students agreed to use mobile learning with google classroom accompanied by practical, efficient peer speech, provided a better understanding of physics concepts, could motivate, be more disciplining, and could establish better relationships with colleagues. Furthermore, the use of mobile learning with google classroom accompanied by peer speech is effective in improving student physics learning outcomes in the medium category with a value of $<N$-Gain $>0.53$.
\end{abstract}

Keywords: mobile learning, google classroom, peer tutor, fundamental physics

DOI: http://dx.doi.org/10.15575/jotalp.v5i2.8052

Received: 25 Maret 2020 ; Accepted: 09 Juli 2020 ; Published: 31 Agustus 2020 


\section{PENDAHULUAN}

Menurut Undang-undang Republik Indonesia Nomor 14 tahun 2005 Pasal 1 tentang guru dan dosen dijelaskan bahwa dosen memiliki tugas utama dalam mentransformasikan, mengembangkan, dan menyebarluaskan ilmu pengetahuan, teknologi, dan seni melalui pendidikan, penelitian, dan pengabdian kepada masyarakat. Kegiatan pendidikan, penelitian, dan pengabdian kepada masyarakat merupakan tridharma perguruan tinggi yang harus dipenuhi oleh dosen. Selanjutnya pada Pasal 5, dosen juga memiliki peranan sebagai agen pembelajaran, pengembang ilmu pengetahuan, teknologi, dan seni, serta pengabdi kepada masyarakat berfungsi untuk meningkatkan mutu pendidikan nasional. Dosen dituntut untuk mengembangan ilmu pengetahuan sesuai dengan bidang keilmuan dosen tersebut. Selanjutnya, Pasal 6 juga menjelaskan kedudukan dosen sebagai tenaga professional bertujuan untuk melaksanakan sistem pendidikan nasional yaitu berkembangnya potensi peserta didik agar menjadi manusia yang beriman dan bertakwa kepada Tuhan yang Maha Esa, berakhlak mulia, sehat, berilmu, cakap, kreatif, mandiri, serta menjadi warga Negara yang demokratis dan bertanggungjawab. Dosen ikut serta dalam mewujudkan tujuan pendidikan nasional. Disamping itu, salah satu tugas keprofesionalan dosen di Pasal 60 adalah merencanakan, melaksanakan proses pembelajaran, serta menilai dan mengevaluasi hasil pembelajaran. Perencanaan yang matang menentukan keterlaksanaan proses pembelajaran yang berkualitas serta diikuti dengan evaluasi yang tepat untuk memperoleh peserta didik yang berkualitas yang sesuai dengan tujuan pendidikan nasional dan era industri 4.0 saat ini.

Era industri 4.0 adalah istilah yang digunakan untuk merujuk pada era dimana terjadi perpaduan teknologi yang mengakibatkan dimensi fisik, biologis, dan digital membentuk suatu perpaduan yang sulit untuk dibedakan. Misalnya, dua orang dapat saling berbagi informasi secara langsung dengan bantuan digital tanpa harus berada pada tempat yang sama atau pada waktu yang bersamaan baik secara fisikis maupun biologis. Terjadinya digitalisasi informasi dan pemanfaatan kecerdasan buatan (artificial intelligence) secara massif di berbagai sektor kehidupan manusia, termasuk di dunia pendidikan, adalah tanda dimulainya era industri 4.0 (Schwab, 2016).

Era revolosi industri 4.0 memberikan dampak terhadap dunia pendidikan. Hal ini sejalan dengan pendapat Hoyles \& Lagrange (2010) yang menyatakan bahwa teknologi digital adalah hal yang paling mempengaruhi sistem pendidikan di dunia saat ini. Hal ini disebabkan karena aspek efektivitas, efisiensi, dan daya tarik yang ditawarkan oleh pembelajaran berbasis teknologi digital. Pembelajaran berbasis teknologi menawarkan banyak kemudahan bagi dunia pendidikan.

Namun, berdasarkan fakta di lapangan, belum tersedianya pembelajaran berbasis teknologi yang dapat memudahkan mahasiswa dalam mengakses materi perkuliahan khususnya dalam mata kuliah Fisika Dasar di Jurusan Tadris Biologi FTIK IAIN Kerinci. Pembelajaran selama ini menggunakan metode diskusi yang disertai tanya jawab antara mahasiswa dengan mahasiswa serta antara dosen dengan mahasiswa. Kegiatan praktikum juga tidak dilaksanakan pada mata kuliah Fisika Dasar ini yang disebabkan oleh tidak tersedianya laboratorium fisika dasar di jurusan tempat penelitian ini dilakukan. Ilmu yang diperoleh sebatas apa yang di bagikan selama proses perkuliahan. Dengan keterbatasan ilmu yang diperoleh, mahasiswa kesulitan dalam mempelajari ilmu fisika.

Berdasarkan uraian diatas, peneliti ingin menghadirkan suatu pembelajaran yang berbasis teknologi yang bisa diakses oleh mahasiswa secara mudah melalui Android mereka masingmasing. Solusi yang ditawarkan berupa penggunaan mobile learning dalam pembelajaran Fisika Dasar dengan menggunakan platform 
gratis berupa google classroom. Koole (2009) berpendapat bahwa "mobile learning offers learners greater access to relevant information, reduced cognitive load, and increased access to other people and systems". Pembelajaran dengan menggunakan mobile learning memberikan kemudahan bagi mahasiswa dalam mengakses materi terbaru dari dosennya serta dapat mengurangi beban kognitif. Selanjutnya Sarrab (2012) juga berpendapat "the mobile learning can be defined as.... educational information and educational resources anywhere at any time". Pembelajaran menggunakan mobile didefinisikan sebagai upaya untuk memperoleh informasi mengenai dunia pendidikan dan dapat memperoleh informasi tersebut dimanapun dan kapanpun. Terdapat empat (4) dimensi dalam pembelajaran mobile yaitu situated learning environment, virtual group awareness/strategies, mobile learner, and mobile coacher. Hal ini sesuai dengan pendapat Jeng (2010) yang menjelaskan dimensi dalam pembelajaran mobile yang disajikan dalam bentuk Gambar 1 di bawah ini.

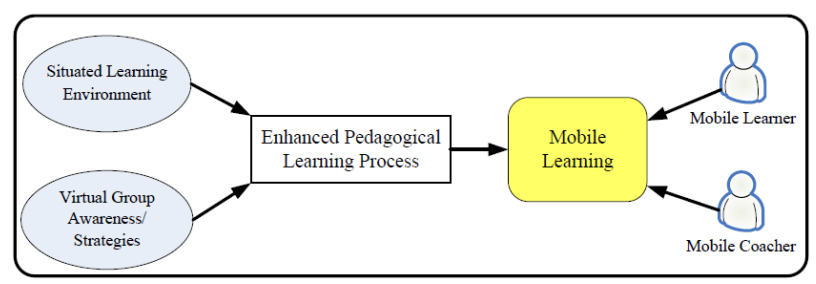

Gambar 1. Atribut penting dalam pembelajaran mobile

Empat dimensi ini berupa pengkondisian lingkungan belajar, strategi kelas virtual yang tepat dalam meningkatkan proses pembelajaran, ponsel peserta didik, serta ponsel pendidik. ElHussein (2010) juga menjelaskan bahwa "mobile learning define mobile learning as wireless and digital devices and technologies, generally produced for the public, used by a learner as he or she participates in higher education". Pembelajaran dengan menggunakan mobile menggunakan wireless dan alat digital, serta teknologi yang bermanfaat bagi peserta didik dalam pendidikan tinggi (mahasiswa). Pembelajaran dengan menggunakan mobile sangat sesuai untuk mahasiswa dalam menghadapi era revolusi industri 4.0 yang sedang di gaungkan saat ini.

Platform yang digunakan dalam penelitian ini yang mendukung pembelajaran mobile adalah google classroom. Hal ini sejalan dengan pendapat Kumar (2019) yang menjelaskan bahwa "google classroom gets students accustomed to this mobile learning platform and its utilization for academic activities". Penggunaan google classroom sesuai untuk menyokong pembelajaran mobile dan memiliki manfaat dalam aktivitas akademik. Aktivitas akademik yang dimaksud disini adalah proses pembelajaran serta proses penilaian dalam proses pembelajaran. Dalam google classroom seorang pendidik dapat menginformasi perkuliahannya dengan melampirkan file materi perkuliahan atau dalam bentuk lainnya yang dapat mendukung proses perkuliahan. Bagian ini dinamai dengan stream line. Hal ini sejalan dengan pendapat Al-Maroof (2018) yang menyatakan bahwa "it provides a stream line of communication and workflow for students". Stream line ini dapat memberikan wadah komunikasi yang mudah untuk pendidik dengan peserta didik serta dapat menginformasikan alur kerja ataupun tugas kepada peserta didik. AlMaroof (2018) juga menambahkan "the google classroom is available as a tool for developing teaching and learning process all over the world". Google classroom ini memang disediakan untuk keperluan dalam pengembangan pengajaran dan proses pembelajaran sehingga sesuai dengan harapan penulis.

Pembelajaran dengan menggunakan mobile juga bisa disandingkan dengan pembelajaran konvensional yang dapat mendukung tercapainya indikator capaian pembelajaran untuk mata kuliah di perguruan tinggi. Hal ini sejalan dengan pendapat Sharples (2009) yang berpendapat bahwa "mobile learning can be integrated with conventional education". Pembelajaran mobile dalam penelitian ini dipadukan dengan dengan metode pembelajaran 
tutor sebaya. Ulfah (2012) menyatakan bahwa "tutor sebaya dikenal dengan pembelajaran teman sebaya atau antar peserta didik, hal ini bisa terjadi ketika peserta didik yang lebih mampu menyelesaikan pekerjaannya sendiri dan kemudian membantu peserta didik lain yang kurang mampu dalam menyelesaikan pekerjaannya". Tutor sebaya merupakan salah satu metode pembelajaran untuk membantu memenuhi kebutuhanpeserta didik". Adapun keunggulan metode tutor sebaya menurut Natawidjaja (1984) berupa (1) adanya suasana hubungan yang lebih dekat dan akrab antara murid yang dibantu dengan murid sebagai tutor yang membantu; (2) bagi tutor sendiri, kegiatan remedial ini merupakan kesempatan untuk pengayaan dalam belajar dan juga dapat menambah motivasi belajar; (3) bersifat efisien, artinya bisa lebih banyak yang dibantu; (4) dapat meningkatkan rasa tanggung jawab dan kepercayaan diri. Berdasarkan keuntungan di atas tutor sebaya merupakan metode yang dapat membantu siswa yang mengalami kesulitan belajar. Pembelajaran tutor sebaya ini juga sesuai untuk digunakan dalam pembelajaran fisika diperguruan tinggi. Hal ini sesuai dengan pendapat Crouch (2001) yang menerapkan pembelajaran tutor sebaya dalam mata kuliah fisika dihasilkan bahwa dengan menggunakan metode tersebut membuat mahasiswa dapat menuntaskan kesulitan-kesulitan dalam materi fisika yang dipelajarinya sehingga pembelajaran akan semakin efektif.

Tujuan dalam penelitian ini dilaksanakan adalah untuk mengetahui tanggapan mahasiswa terhadap penggunaan mobile learning disertai teknik tutor sebaya dalam pembelajaran Fisika Dasar serta untuk mengetahui efektivitas mobile learning dengan menggunakan platform google classroom dalam mata kuliah Fisika Dasar di jurusan tadris biologi. Tanggapan yang dimaksud dalam penelitian ini adalah tanggapan mahasiswa terkait kemudahan yang dirasakan dalam penggunaan mobile learning disertai teknik tutor sebaya, efisiensi waktu, kepraktisan, peningkatan kemampuan teknologi, menanamkan rasa tanggung jawab dan disiplin serta bagaimana dengan penggunaan mobile learning disertai teknik tutor sebaya ini dapat membuat mereka lebih cepat memahami materi dan termotivasi untuk menjadi lebih baik dalam setiap kegiatan perkuliahan. Efektivitas yang dimaksud adalah dengan melihat kategori peningkatan hasil belajar Fisika Dasar mahasiswa. Materi fisika dasar yang dimaksud dalam penelitian ini adalah materi dinamika Newton yang diajarkan selama 4 jam pertemuan (JP) yang setiap JPnya berdurasi 50 menit. Instrumen yang digunakan dalam penelitian ini adalah angket tanggapan mahasiswa yang terdiri dari delapan indikator berupa a) kemudahan mahasiswa dalam mengakses materi perkuliahan dalam penggunaan mobile learning disertai teknik tutor sebaya dalam mata kuliah Fisika Dasar, b) kepraktisan dalam penggunaan mobile learning disertai teknik tutor sebaya dalam perkuliahan Fisika Dasar, c) peningkatan mahasiswa dalam menggunakan teknologi dengan kehadiran mobile learning disertai teknik tutor sebaya, d) efisiensi waktu dalam pengiriman tugas individual dalam perkuliahan, e) kedisiplinan mahasiswa dalam melaksanakan proses perkuliahan Fisika Dasar, f) kemudahan dalam memperoleh pemahaman yang benar dalam konsep Fisika, g) keharmonisan hubungan dengan rekan sejawat sehingga lebih termotivasi dalam perkuliahan, dan h) penanaman rasa tanggung jwab dan rasa percaya diri dalam diri mahasiswa. Selanjutnya, instrumen untuk mengukur efektivitas penggunaan mobile learning disertai teknik tutor sebaya dalam meningkatkan hasil belajar Fisika Dasar mahasiswa menggunakan soal hasil belajar Fisika Dasar Mahasiswa dalam bentuk essay.

\section{METODE PENELITIAN}

Pendekatan yang digunakan dalam penelitian ini adalah pendekatan kuantitatif. Pendekatan kuantitatif merupakan pendekatan yang melibatkan kegiatan eksperimen, variabel, dan perlakuan serta digunakan untuk menguji suatu 
teori atau konsep (Creswell, 2003). Hal ini juga sejalan dengan pendapat Priyono (2008) yang menyatakan bahwa "penelitian kuantitatif mendasarkan pada teori". Teori yang mendukung perlakuan yang kita berikan sudah kuat dan selanjutnya peneliti melakukan pengujian teori tersebut dalam suatu kelas penelitian. Metode yang digunakan dalam penelitian ini adalah pre experimental. Metode pre experimental merupakan penelitian yang menggunakan satu kelas dan menerapkan perlakuan kepada kelas tersebut. Metode ini tidak menggunakan kelas pembanding yaitu kelas kontrol untuk dibandingkan dengan kelas eksperimen dimana perlakuan itu diterapkan (Creswell, 2003). Desain dalam penelitian ini menggunakan one group pretest posttest design dimana hanya satu kelas yang duji sebelum dan sesudah perlakuan diterapkan. Adapun diagram yang menjelaskan desain penelitian one group pretest posttest design terdapat pada Tabel 1.

Tabel 1. Diagram Desain Penelitian

\begin{tabular}{ccc}
\hline 0 & $\mathrm{X}$ & $\mathrm{O}$ \\
\hline Pretest & Treatment & Posttest \\
\hline
\end{tabular}

Teknik pengumpulan data yang digunakan untuk menjawab pertanyaan penelitian ini adalah angket tanggapan mahasiswa terkait penggunanaan mobile learning dengan google classroom disertai tutor sebaya dan soal hasil belajar Fisika Dasar. Instrumen yang digunakan dalam penelitian ini adalah angket tanggapan dan soal hasil belajar dalam bentuk essay.

Populasi merupakan sejumlah individu yang memiliki karakteristik yang sama. Populasi bisa saja berbentuk kelas, sekolah, atau fasilitas lainnya (Fraenkel, 1993). Populasi dalam penelitian ini adalah mahasiswa semester 1 tahun ajaran 2019/2020 yang terdiri dari 3 kelas. Teknik yang digunakan dalam penentuan sampel adalah random sampling dengan metode cluster random sampling. Metode ini melakukan pemilihan sampel secara acak dari populasi berupa cluster atau kelompok. Mahasiswa semester 1 lokal A yang terpilih menjadi sampel penelitian dengan jumlah 28 mahasiswa.

Penelitian dimulai dengan pemberian pretest terlebih dahulu kepada mahasiswa berupa soal hasil belajar dinamika Newton sebanyak delapan soal. Selanjutnya mahasiswa dikenalkan dengan platform gratis berupa google classroom yang akan digunakan dalam pembelajaran mobile serta dikombinasikan dengan pembelajaran konvensional berupa pembelajaran tutor sebaya. Setelah terlaksana pembelajaran dinamika Newton sebanyak 4 jam pertemuan dalam durasi waktu 200 menit, peneliti selanjutnya memberikan soal posttest yang jumlah soalnya sama dengan pretest namun setara. Setara yang dimaksud adalah tingkat kesulitan soal sama namun soalnya berbeda. Untuk mengetahui efektivitas penggunaan mobile learning disertai tutor sebaya, peneliti memperolehnya dari nilai $<\mathrm{N}$-Gain $>$ hasil belajar mahasiswa pada materi dinamika Newton dengan persamaan berikut:

$$
<N-\text { Gain }>=\frac{<\text { Posttest }>-<\text { Pr etest }>}{S_{\text {maksideal }}-<\text { Pr } \text { etest }>}
$$

Keterangan:

$\begin{array}{ll}<\text { Posttest }> & =\text { Skor rata-rata posttest } \\ <\text { Pretest }> & =\text { Skor rata-rata pretest } \\ \mathrm{S}_{\text {maks.ideal }} & =\text { Skor maksimum ideal }\end{array}$

Tabel 2. Kategori Rentang Nilai <N-Gain>

\begin{tabular}{ccc}
\hline No. & Rentang & $\begin{array}{c}\text { Kategori Rata- } \\
\text { rata } \\
\text { Peningkatan }\end{array}$ \\
\hline 1 & $<\mathrm{N}-$ Gain $>\geq 0,7$ & Tinggi \\
\hline 2 & $0,3 \leq<\mathrm{N}-$ Gain $><0,7$ & Sedang \\
\hline 3 & $<\mathrm{N}-$ Gain $><0,3$ & Rendah \\
\hline
\end{tabular}

(Hake, 1999) 


\section{HASIL DAN PEMBAHASAN}

Hasil dan pembahasan penelitian ini sesuai dengan tujuan masalah penelitian yang dikemukakan di bagian pendahuluan.

\section{Data tanggapan mahasiswa terkait penggunaan mobile learning dengan google classroom disertai tutor sebaya}

Tanggapan mahasiswa terkait penggunaaan mobile learning dengan google classroom disertai tutor sebaya diperoleh dari angket tanggapan mahasiswa yang terdiri dari delapan pertanyaan. Delapan pertanyaan serta banyaknya jawaban dapat dilihat pada Tabel 3 berikut:

Tabel 3. Hasil Data Tanggapan Mahasiswa

\begin{tabular}{|c|c|c|c|}
\hline No & Pertanyaan & $\begin{array}{c}\text { Jawaban } \\
\text { “ya"/"Setuju” }\end{array}$ & $\begin{array}{c}\text { Jawaban } \\
\text { "Tidak"/ } \\
\text { "TIdak } \\
\text { Setuju" }\end{array}$ \\
\hline 1 & $\begin{array}{l}\text { Apakah dengan } \\
\text { penggunaan } \\
\text { mobile learning } \\
\text { dengan google } \\
\text { classroom } \\
\text { dapat } \\
\text { mempermudah } \\
\text { Ananda dalam } \\
\text { mengakses } \\
\text { materi kuliah? }\end{array}$ & 25 & 3 \\
\hline 2 & $\begin{array}{l}\text { Apakah } \\
\text { platform google } \\
\text { classroom dalam } \\
\text { mobile learning } \\
\text { mudah dan } \\
\text { praktis untuk } \\
\text { digunakan? } \\
\end{array}$ & 28 & 0 \\
\hline 3 & $\begin{array}{l}\text { Apakah dengan } \\
\text { penggunaan } \\
\text { mobile learning } \\
\text { dengan google } \\
\text { classroom dapat } \\
\text { menambah } \\
\text { kemampuan } \\
\text { Ananda dalam } \\
\text { menggunakan } \\
\text { teknologi dalam }\end{array}$ & 28 & 0 \\
\hline
\end{tabular}

\begin{tabular}{|c|c|c|c|}
\hline No & Pertanyaan & $\begin{array}{c}\text { Jawaban } \\
\text { “ya"/"Setuju" }\end{array}$ & $\begin{array}{c}\text { Jawaban } \\
\text { “Tidak"/ } \\
\text { "TIdak } \\
\text { Setuju" }\end{array}$ \\
\hline & perkuliahan? & & \\
\hline 4 & $\begin{array}{l}\text { Apakah dengan } \\
\text { penggunaan } \\
\text { mobile learning } \\
\text { dengan google } \\
\text { classroom dapat } \\
\text { membuat } \\
\text { waktumu lebih } \\
\text { efisien dalam } \\
\text { mengirim } \\
\text { tugas? }\end{array}$ & 27 & 1 \\
\hline 5 & $\begin{array}{l}\text { Apakah dengan } \\
\text { penggunaan } \\
\text { mobile learning } \\
\text { dengan google } \\
\text { classroom dapat } \\
\text { membuatmu } \\
\text { lebih disiplin } \\
\text { dalam proses } \\
\text { perkuliahan? }\end{array}$ & 28 & 0 \\
\hline 6 & $\begin{array}{l}\text { Apakah dengan } \\
\text { penggunaan } \\
\text { mobile learning } \\
\text { dengan google } \\
\text { classroom } \\
\text { disertai tutor } \\
\text { sebaya dapat } \\
\text { membuatmu } \\
\text { lebih cepat } \\
\text { memahami } \\
\text { materi perkuliahan } \\
\text { fisika dasar? }\end{array}$ & 26 & 2 \\
\hline 7 & $\begin{array}{l}\text { Apakah dengan } \\
\text { penggunaan } \\
\text { mobile learning } \\
\text { dengan google } \\
\text { classroom } \\
\text { disertai tutor } \\
\text { sebaya dapat } \\
\text { membuatmu } \\
\text { lebih akrab } \\
\text { dengan rekan } \\
\text { sejawat dan } \\
\text { lebih } \\
\text { termotivasi } \\
\text { untuk giat }\end{array}$ & 28 & 0 \\
\hline
\end{tabular}




\begin{tabular}{|c|c|c|c|}
\hline No & Pertanyaan & $\begin{array}{c}\text { Jawaban } \\
\text { "ya"/"Setuju" }\end{array}$ & $\begin{array}{l}\text { Jawaban } \\
\text { "Tidak"/ } \\
\text { "TIdak } \\
\text { Setuju" }\end{array}$ \\
\hline & belajar? & & \\
\hline 8 & $\begin{array}{l}\text { Apakah dengan } \\
\text { penggunaan } \\
\text { mobile learning } \\
\text { dengan google } \\
\text { classroom } \\
\text { disertai tutor } \\
\text { sebaya dapat } \\
\text { meningkatkan } \\
\text { rasa tanggung } \\
\text { jawab dan } \\
\text { percaya diri } \\
\text { Ananda? }\end{array}$ & 28 & 0 \\
\hline
\end{tabular}

Berdasarkan tabel diatas, maka dapat dihitung persentase mahasiswa yang menanggapi penggunaan mobile learning dengan google classroom ini dengan positif. Terdapat $89,2 \%$ mahasiswa yang setuju bahwa penggunaan mobile learning dengan google classroom dapat memudahkan mahasiswa dalam mengakses materi perkuliahan. Materi perkuliahan diberikan oleh dosen pengampu sebelum perkuliahan dimulai dengan mengunggah materi pada bagian stream line, sehingga mahasiswa dapat mengakses materi dimana saja dan kapan saja. Hal ini telah sesuai dengan pendapat Quinn (2011) yang mengatakan dengan penggunaan mobile learning dapat mmudahkan mahasiswa dalam memperoleh materi secara mandiri dimanapun mahasiswa tersebut berada. Namun ada $10,8 \%$ mahasiswa yang tidak setuju terkait hal ini yang disebabkan karena tidak adanya jaringan di dusun tempat mereka tinggal dan ada yang belum sanggup membeli paket data akan dirugikan oleh penggunaan mobile learning tersebut. Solusi dari tanggapan negatif mahasiswa tersebut yang diberikan oleh peneliti adalah dengan mengunduh terlebih dahulu materi yang diberikan oleh dosen pengampu sehari sebelum perkuliahan dimulai dengan menggunakan wifi kampus secara gratis. Dari penelitian ini terlihat bahwa dalam penggunaan mobile learning peranan wifi memang sangat penting demi kelancaran proses pembelajaran. Hal ini sejalan dengan pendapat Koole (2009) yang menjelaskan bahwa peranan wifi sangat penting dalam pembelajaran mobile.

Pada pertanyaan kedua, 100\% mahasiswa setuju penggunaan google classroom mudah digunakan. Mahasiswa cukup menggunakan akun gmail masing-masing dan mengetahui kode kelas yang dosen pengampu gunakan. Hal ini sejalan dengan pendapat Gunawan (2018) yang menjelaskan bahwa untuk mengundang mahasiswa ke dalam google classroom cukup menggunakan email dan kode kelas dari google classroom yang telah dibuat, dan selanjutnya mahasiswa dapat mencari informasi terkait perkuliahannya dengan mudah. Selanjutnya, 100\% mahasiswa juga setuju bahwa penggunaan mobile learning ini dapat meningkatkan kemampuan siswa dalam menggunakan teknologi. Mobile learning ini mendukung pembelajaran era revolusi industri 4.0.

Mahasiswa yang menyatakan setuju bahwa dengan kehadiran mobile learning dengan google classroom dapat membuat waktu mahasiswa tersebut lebih efisien dalam mengirim tugas sebesar 96,4\%. Terdapat satu mahasiswa yang tidak setuju yang masih disebabkan tidak adanya jaringan di dusun tempat mereka tinggal. Hal ini sejalan dengan Al-Maroof (2018) yang menyatakan "...the usage of Google classroom due to its usefulness, easy to use, and its practicality in accomplishing the intended tasks". Mahasiswa dapat dengan praktis atau mudah mengirim tugas dengan menggunakan google classroom. Semua mahasiswa setuju dengan persentase $100 \%$ terkait penggunaan mobile learning dengan google classroom dapat membuat mahasiswa tersebut lebih disiplin menjalankan proses perkuliahan. Sebagai contoh, mahasiswa tepat waktu dalam mengirim tugas disetiap pertemuan dan dapat mengerjakan kuis sesuai dengan durasi waktu yang diberikan. Hal ini sesuai dengan pendapat (Naismith, 2006) yang menjelaskan perlunya manajemen waktu dalam 
pembelajaran mobile agar dapat tercapai tujuan pembelajaran yang dikehendaki.

Penggunaan mobile learning dengan google classroom disertai tutor sebaya dapat membuat lebih cepat memahami materi perkuliahan Fisika Dasar telah disetujui oleh mahasiswa sebesar 92,8\%. Hal ini sesuai dengan Crouch (2001) yang menjelaskan bahwa dengan pembelajaran tutor sebaya ini dapat mengatasi kesulitan-kesulitan yang diperoleh selama memperlajari materi fisika, dan hal ini juga disetujui oleh mahasiswa yang penulis teliti. Kesulitan dapat dipecahkan bersama dengan waktu yang lebih cepat daripada mengatasi kesulitan tersebut seorang diri. Selanjutnya, 100\% mahasiswa menyetujui bahwa dengan penggunaan mobile learning dengan google classroom disertai tutor sebaya dapat membuat mereka lebih akrab dengan rekan sejawat dan lebih termotivasi untuk giat belajar. Pembagian mahasiswa disesuaikan dengan berapa mahasiswa yang menuntas kuis secara tepat. Mahasiswa yang berhasil dalam kuis akan dipasangkan secara acak dengan teman yang mungkin selama ini mereka tidak begitu akrab sehingga dapat menjadi akrab. Mahasiswa akan lebih giat mempelajari penyelesaian soal kuis karena mereka juga ingin saling take and give. Adakalanya mereka menerima perbaikan ilmu dari teman sejawatnya dan ada pula saatnya mereka memberikan perbaikan ilmu kepada teman sejawatnya sehingga mahasiswa akan senantiasa termotivasi untuk menjadi lebih baik. Penggunaan mobile learning dengan google classroom disertai tutor sebaya dapat meningkatkan rasa tanggung jawab dan percaya diri mahasiswa disetujui oleh seluruh mahasiswa. Mahasiswa merasa percaya diri dalam menjelaskan ilmunya dan memiliki rasa tanggung jawab untuk menuntaskan kesalahpahaman teman sejawatnya. Setiap akhir pertemuan, semua teman sejawat yang dibantu akan menampilkan kembali perbaikan ilmu yang diperoleh dari teman sejawatnya.

\section{Data Hasil Belajar Mahasiswa}

Jenis soal hasil belajar yang diberikan oleh penulis adalah soal dalam bentuk essay sebanyak delapan soal yang membahas tentang dinamika Newton. Soal diturunkan dari indikator capaian pembelajaran yang sudah terangkum dalam Rencana Pembelajaran Semester di mata kuliah Fisika Dasar. Hasil belajar di awal yang disebut dengan pretest perlu diujikan agar mengetahui kondisi awal pengetahuan mahasiswa terkait materi. Sebelum dilaksanakan pretest, mahasiswa sudah diberi tahu untuk belajar mandiri di rumah dalam menjawab soal tersebut. Hasil yang diperoleh berupa nilai rata-rata pretest (<pretest $>$ ) sebesar 26,43 dari nilai maksimal 100. Selanjutnya diterapkanlah perlakukan berupa penggunaan mobile learning dengan google classroom disertai pembelajaran tutor sebaya. Perlakuan diberikan selama 4 jam pertemuan. Hasil belajar sesudah treatment perlu untuk dilakukan agar dapat mengetahui seberapa besar peningkatan hasil belajar mahasiswa yang telah diperolehnya setelah penerapan tersebut. Nilai rata-rata posttest (<posttest $>$ ) yang diperoleh sebesar 65,62 dari nilai maksimal 100, sehingga secara mudah dapat diketahui nilai rata-rata $\mathrm{N}$-Gain $(<\mathrm{N}$-Gain $>)$ yang sekaligus mengindikasikan seberapa besar efektifnya perlakuan tersebut. Nilai rata-rata NGain diperoleh melalui persaman:

$<N-$ Gain $>=\frac{65,62-26,43}{100-26,43}=0,53$

Dari persamaan tersebut, diperoleh bahwa nilai $<\mathrm{N}$-Gain $>$ sebesar 0,53 yang berada pada kategori sedang. Nilai <N-Gain $>$ menunjukkan hasil belajar mahasiswa mengalami peningkatan dalam kategori sedang yang mengindikasikan bahwa terdapat efektivitas penggunaan mobile learning dengan google classroom disertai tutor sebaya pada mata kuliah fisika dasar di Jurusan Tadris Biologi FTIK IAIN Kerinci.

Kategori peningkatan hasil belajar mahasiswa dalam kategori sedang tersebut disebabkan oleh 
beberapa kendala dalam proses perkuliahan diantaranya a) tidak semua mahasiswa yang mengakses materi sebelum perkuliahan berlangsung sehingga tidak semua mahasiswa yang memiliki pengetahuan awal dalam perkuliahan, b) masih adanya mahasiswa yang mengirim tugas tidak tepat pada waktunya yang disebabkan oleh terkendalanya jaringan di dusun tempat mereka tinggal, dan c) keberhasilan mahasiswa yang dibantu oleh mahasiswa yang berhasil dalam kuis dalam kegiatan tutor sebaya tidak sepenuhnya memperoleh perbaikan ilmu yang baik yang berdampak pada hasil belajar setelah penggunaan mobile learning disertai teknik tutor sebaya yang masih dalam katergori sedang.

\section{KESIMPULAN}

Kesimpulan yang diperoleh dalam penelitian ini adalah diperolehnya tanggapan positif mahasiswa terhadap penggunaan mobile learning dengan google classroom disertai tutor sebaya. Selanjtunya, penggunaan mobile learning dengan google classroom disertai tutor sebaya efektif untuk diterapkan dalam mata kuliah Fisika Dasar karena mampu meningkatkan hasil belajar mahasiswa dalam kategori sedang. Saran yang ingin disampaikan kepada mahasiswa agar lebih mandiri dalam berusaha, kesuksesan mobile learning ini juga tergantung dari kemandirian mahasiswa dalam mencari ilmu dan berpikir cerdas dalam menutupi kelemahan yang dirasakan akan mengganggu proses pembelajaran mobile ini.

\section{DAFTAR PUSTAKA}

Al-Maroof, R. A. S., \& Al-Emran, M. (2018). Students acceptance of Google classroom: An exploratory study using PLS-SEM approach. International Journal of Emerging Technologies in Learning (iJET), 13(06), 112-123.

Creswell, J. W. (2003). Research Design: Qualitative, quantitative, and mixed methods approaches (2nded.). London: Sage Publication, Inc

Crouch, C. H., \& Mazur, E. (2001). Peer instruction: Ten years of experience and results. American journal of physics, 69(9), 970-977.

Departemen Pendidikan Nasional. (2005). Undang-Undang Nomor 14 Tahun 2005. Tentang Guru dan Dosen. Jakarta: Depdiknas

El-Hussein, M. O. M., \& Cronje, J. C. (2010). Defining mobile learning in the higher education landscape. Journal of Educational Technology \& Society, 13(3), 12-21.

Fraenkel, J.R and Wallen, N.E. (1993). How To Design And Evaluate Research in Education ( $2^{\text {nd }}$ ed.). New York: Mc Graw-Hill Book Co.

Gunawan, F. I., \& Sunarman, S. G. (2018, February). Pengembangan Kelas Virtual Dengan Google Classroom Dalam Keterampilan Pemecahan Masalah (Problem Solving) Topik Vektor Pada Siswa Smk Untuk Mendukung Pembelajaran. In Prosiding Seminar Nasional Pendidikan Matematika Etnomatnesia.

Hake, R. (1999). Analyzing Change/Gain Scores. Indiana: Indiana University

Hoyles, C., \& Lagrange, J.-B. (Eds.). (2010). Mathematics education and technologyRethinking the terrain. New York, NY/ Berlin, Germany: Springer.

Jeng, Y. L., Wu, T. T., Huang, Y. M., Tan, Q., \& Yang, S. J. (2010). The add-on impact of mobile applications in learning strategies: A review study. Journal of Educational Technology \& Society, 13(3), 3-11.

Koole, M. L. (2009). A model for framing mobile learning. Mobile learning: Transforming the delivery of education and training, 1(2), 2547.

Kumar, J. A., \& Bervell, B. (2019). Google Classroom for mobile learning in higher education: Modelling the initial perceptions of students. Education and 
Information Technologies, 24(2), 17931817.

Naismith, L., \& Corlett, D. (2006). Reflections on success: A retrospective of the mLearn conference series 2002-2005.

Natawidjaja, Rochman. (1984). Pengajaran Remidial. Jakarta:Percetakan Negara RI

Priyono. (2008). Metode Penelitian Kuantitatif. Sidoarjo: Zifatama Publishing

Quinn, C. (2011). Mobile learning: Landscape and trends. The eLearning Guild Research.

Sarrab, M., Elgamel, L., \& Aldabbas, H. (2012). Mobile learning (m-learning) and educational environments. International journal of distributed and parallel systems, 3(4), 31.

Schwab, Klaus. (2016). The Fourth Industrial Revolution: What it means, how to respond. Disadur dari https://www.weforum.org/agenda/2016/ $01 /$ the-fourth-industrial-revolution-whatit means-and-how-to-respond/

Sharples, M., Arnedillo-Sánchez, I., Milrad, M., \& Vavoula, G. (2009). Mobile learning. In Technology-enhanced learning (pp. 233249). Springer, Dordrecht.

Ulfah, M. (2012). Optimalisasi hasil belajar IPA tentang sistem gerak pada manusia melalui metode diskusi dengan tehnik pembelajaran tutor sebaya. Jurnal Pendidikan Tindakan Kelas, 3(1). 